\title{
Mapping genes governing flower architecture and pollen development in a double mutant population of carrot
}

\author{
Holger Budahn ${ }^{1 *}$, Rafał Barański ${ }^{2}$, Dariusz Grzebelus ${ }^{2}$, Agnieszka Kiełkowska $^{2}$, Petra Straka ${ }^{3}$, \\ Kai Metge ${ }^{3}$, Bettina Linke ${ }^{4}$ and Thomas Nothnagel ${ }^{1}$ \\ ${ }^{1}$ Institute for Breeding Research on Horticultural Crops, Federal Research Centre for Cultivated Plants, Julius Kühn-Institute, Quedlinburg, Germany \\ ${ }^{2}$ Department of Genetics, Plant Breeding and Seed Science, Faculty of Horticulture, University of Agriculture, Kraków, Poland \\ ${ }^{3}$ Institute for Biosafety in Plant Biotechnology, Federal Research Centre for Cultivated Plants, Julius Kühn-Institute, Quedlinburg, Germany \\ ${ }^{4}$ Department of Biology, Humboldt University, Berlin, Germany
}

\section{Edited by:}

Klaus Pillen,

Martin-Luther-University

Halle-Wittenberg, Germany

Reviewed by:

Daniel Pinero, Universidad Nacional

Autónoma de México, Mexico

Matthew R. Willmann, University of

Pennsylvania, USA

\section{${ }^{*}$ Correspondence:}

Holger Budahn, Institute for

Breeding Research on Horticultural

Crops, Julius Kühn-Institute, Federal

Research Centre for Cultivated

Plants, Erwin-Baur-Str. 27, D-06484

Quedlinburg, Germany

e-mail: holger.budahn@jki.bund.de
A linkage map of carrot (Daucus carota L.) was developed in order to study reproductive traits. The $\mathrm{F}_{2}$ mapping population derived from an initial cross between a yellow leaf (yel) chlorophyll mutant and a compressed lamina (cola) mutant with unique flower defects of the sporophytic parts of male and female organs. The genetic map has a total length of $781 \mathrm{cM}$ and included 285 loci. The length of the nine linkage groups (LGs) ranged between 65 and $145 \mathrm{cM}$. All LGs have been anchored to the reference map. The objective of this study was the generation of a well-saturated linkage map of $D$. carota. Mapping of the cola-locus associated with flower development and fertility was successfully demonstrated. Two MADS-box genes (DcMADS3, DcMADS5) with prominent roles in flowering and reproduction as well as three additional genes (DcAOX2a, $D c A O X 2 b, D c C H S 2)$ with further importance for male reproduction were assigned to different loci that did not co-segregate with the cola-locus.

Keywords: Daucus carota, linkage map, MADS-box genes, male gametogenesis, alternative oxidase, chalcone synthase

\section{INTRODUCTION}

Carrot is the second most economically valuable vegetable in the European Union and is also of worldwide significance. Increased production area and improved productivity highlight its economical importance in North America, Asia, and Europe (http://faostat.fao.org/). Over the last few decades, carrot consumption has continuously grown (Simon et al., 2009).

Daucus carota is a typical biannual diploid $(2 \mathrm{n}=2 \mathrm{x}=18)$ outcrossing species with a relatively small genome estimated as $473 \mathrm{Mb}$. Carrot chromosomes are small but morphologically distinguishable (Schrader et al., 2003). Within the large family of Apiacea, carrot is the best characterized species at the genetic and molecular level. Comprehensive research has been performed on the characterization of metabolite contents, morphological traits and resistances (for review see Brandeen and Simon, 2007; Simon et al., 2008). On the other hand, knowledge on genes controlling reproduction and flowering is yet limited. To facilitate genetic characterization by improved mapping studies, several tools have been made available in recent years. This includes a deep coverage BAC library (Cavagnaro et al., 2009), assignment of linkage groups (LGs) to chromosomes by fluorescence in situ hybridization (Iovene et al., 2011) and de novo assembly of the carrot transcriptome (Iorizzo et al., 2011) and opens advanced perspectives for carrot research and breeding.

Improved knowledge on genetic control mechanisms for plant reproduction traits such as flowering time, fertility and seed set is of essential importance for the breeding process, especially for the stabilization of seed yield under different environmental conditions. One of the key steps is the determination of the basal floral architecture, i.e., the specification of sepals, petals, stamens, and carpels. Based on studies in model plants like Arabidopsis and Antirrhinum, the ABC model of flower development was proposed (Coen and Meyerowitz, 1991). The model was further extended by D- and E-class genes to include the advanced development of reproductive organs (Pelaz et al., 2000; Theissen, 2001). The majority of these genes belong to the MADS-box gene family of transcription factors (Schwarz-Sommer et al., 1990). MADS-box genes can be grouped into different clades with subfamily-specific functions in flower development (Becker and Theissen, 2003; Parenicova et al., 2003). Genes of these groups play a critical role in the determination of the identity of two neighboring flower whorls according to the ABCDE model. In the carrot, Linke et al. (2003) have identified five MADS-box genes (DcMADS1 to 5) and assigned them to the previously defined groups SQUAMOSA, GLOBOSA, DEFICIENS, AGAMOUS, and SEPALLATA1.

Other classes of genes are involved in the development of functional pollen and are important for fertility/sterility. The alternative oxidase (AOX) is a mitochondrial ubiquinol:oxygen oxidoreductase (Affourtit et al., 2002). It is encoded by a small nuclear multigene family ( $A O X 1$ and $A O X 2$ ). For the gene $A O X 2 b$ a striking effect on male and female gametogenesis was shown in soybean. Its regulation depends on the tissue and the developmental stage (Finnegan et al., 1997; Djajanegara et al., 2002). A significant effect on pollen abortion and pollen germination was measured (Chai et al., 2010). In the pistils of transgenic antisense 
GmAOX2b soybean plants, a higher portion of immature-sized and non-fertile embryo sacs were observed. In addition, significant changes of the expression level for alternative oxidase in maize mitochondrial mutants were identified (Karpova et al., 2002).

Another enzyme with effects at particular stages of anther and pollen development is chalcone synthase (CHS), one of the key enzymes involved in the flavonoid biosynthesis pathway. Flavonoids are important for pollen development and plant fertility in several plant species (Dobritsa et al., 2010 and references therein). CHS has been reported as a potential sex-determination gene that is expressed in male cones of Pinus (Walden et al., 1999) and in male flower buds of Silene (Ageez et al., 2005). Significant effects of CHS on different types of nuclear male sterility were demonstrated for maize (Mo et al., 1992), petunia (Taylor and Jorgensen, 1992; van der Meer et al., 1992) and tobacco (Atanassov et al., 1998). In plants carrying the cytoplasmic male sterility trait (CMS), the deficiency of flavonoids caused by inhibition of CHS expression was strongly associated with pollen abortion (Yang et al., 2008). A role of CHS genes in the formation of the exine during microspore development has been reported in Arabidopsis (Dobritsa et al., 2010).

The first well-saturated map of all nine carrot LGs was generated by Just et al. (2007). Transposon display (td) markers were integrated into that map by Grzebelus et al. (2007) using DcMaster, a family of PIF/Harbinger-like transposable elements identified in Daucus. Simple sequence repeats (SSRs) have great advantages in comparison to other marker classes and were applied in research on carrot gene flow and genetic diversity (Rong et al., 2010; Barański et al., 2012). High reproducibility, abundance and a codominant inheritance make SSR markers particularly well suited for anchoring different maps of the same or closely related species. Niemann et al. (1997) have developed the first set of SSR markers for carrot and later assigned 19 SSR markers to a carrot linkage map (Niemann, 2001). Other sets of SSR markers were described by Umehara et al. (2005) and Clotault et al. (2010). By far more SSR markers became available to anchor new D. carota linkage maps, when Cavagnaro et al. (2011) provided a set of 300 SSR markers for carrot and assigned 55 of them to all nine LGs. In parallel, Iorizzo et al. (2011) has described a set of SSR markers from transcribed sequences (eSSR). These sets of SSR markers were used by Alessandro et al. (2013) for mapping $V r n 1$, a gene controlling early flowering and $R f 1$, a restorer gene for the petaloid-type of CMS in carrot. Yildiz et al. (2013) reported the mapping of anthocyanin biosynthesis genes on five individual carrot LGs. Recently, a carrot map on the base of Diversity Array Technology (DArT) markers became available (Grzebelus et al., 2014).

Due to the high genetic diversity within the carrot with substantial allelic variability (Macko and Grzebelus, 2008; Grzebelus et al., 2014), an extended genetic map will be advantageous to allocate and improve genetic information and to facilitate the possibility to set up meta-analyses of favorable genetic traits (Brachi et al., 2011). The objective of the present study was the generation of a well-saturated linkage map of $D$. carota comprising markers linked to known and new loci associated with flower development and fertility.

\section{MATERIALS AND METHODS PLANT MATERIAL}

The $\mathrm{F}_{2}$ mapping population DM19 was developed from an initial cross of the homozygous recessive yellow leaf (yel yel) mutant as the maternal parent and the compressed lamina (cola cola) mutant as the pollen parent. The yel-mutant is easily distinguishable from the wild-type by the yellow leaf color due to chlorophyll deficiency (Nothnagel and Straka, 2003). The cola-mutant is characterized by compact small leaves. The flower architecture of cola-plants did not correspond to one of the major "homeotic" phenotypes as described by the ABCDE model indicating that the reproductive organs have acquired a correct identity. Instead, rather advanced stages of reproductive organ differentiation were impaired. The female organs revealed a slight, but unique difference of the ovary position that has changed from an inferior position (epigynous flower type) to a rather superior position (hypogynous flower type) as was shown in Figure 1C. Thus, the ovary of cola-mutant flowers was located above the insertion point of the perianthring. This trait is always associated with the trait "anther/locule defect" of the cola-type flowers, indicating an irregular structure of several theca and/or locules as was previously shown by histomorphological investigation (Nothnagel et al., 2005). For flower characterization of the mapping population we have used the trait "epigynous/hypogynous" because it is easy to characterize and do not require additional histological analyses. Hence, the colamutant flowers revealed defects of the sporophytic parts of both, male and female organs as a result of an impaired advanced differentiation. In contrast, the yel-parent of the mapping population revealed a wild-type phenotype for flower architecture.

Plants were grown in $16 \mathrm{~cm}$ plastic pots in a sand-humus mixture (v/v 3/1) in the greenhouse. To induce flowering, the plants were vernalized in a climatic chamber at $5^{\circ} \mathrm{C}$ for 12 weeks in the dark. Flowering plants were isolated and crossed manually to produce $\mathrm{F}_{1}$ plants (YEL yel COLA cola). True hybrids expressed the wild-type phenotype and were self-pollinated to produce $F_{2}$ seeds. Leaf color and leaf shape of the $\mathrm{F}_{2}$ plants were evaluated 30,60 , and 90 days after sowing. Bolting status of the $F_{2}$ plants was observed visually approximately each 5 days after vernalization and replantation in the glasshouse. The flower architecture was investigated using a stereoscopic microscope.

For the statistical analyses was used the software Systat 13 (Chicago, IL: Systsat Software, Inc., 2009). Data of $\mathrm{F}_{2}$ - segregation were analyzed using the $\chi^{2}$-test to determine the goodness of fit for Mendelian inheritance (9:3:3:1 or 3:1, respectively).

\section{ANALYSIS OF POLLEN VIABILITY}

The pollen viability was determined by vital staining of microspore cells, using fluorescein diacetate (FDA) according to Heslop-Harrison and Heslop-Harrison (1970). From ten plants of the cola-mutant and ten plants of the wild-type, five protandrous flowers were collected and the anthers were immediately suspended in $0.5 \mathrm{ml}$ of a solution containing $75 \mathrm{mg} / \mathrm{ml}$ sucrose and $1 \mathrm{mg} / \mathrm{ml}$ FDA (Serva, Heidelberg, Germany). Pollen viability was determined as ratio of pollen emitting strong fluorescence when subjected to UV light using Axioskop 2 (Zeiss, Oberkochen, Germany) equipped with a fluorescence filter set 44 [excitation BP 475/40 (455-495 nm)/emission BP 530/50 (505-555 nm)]. At 

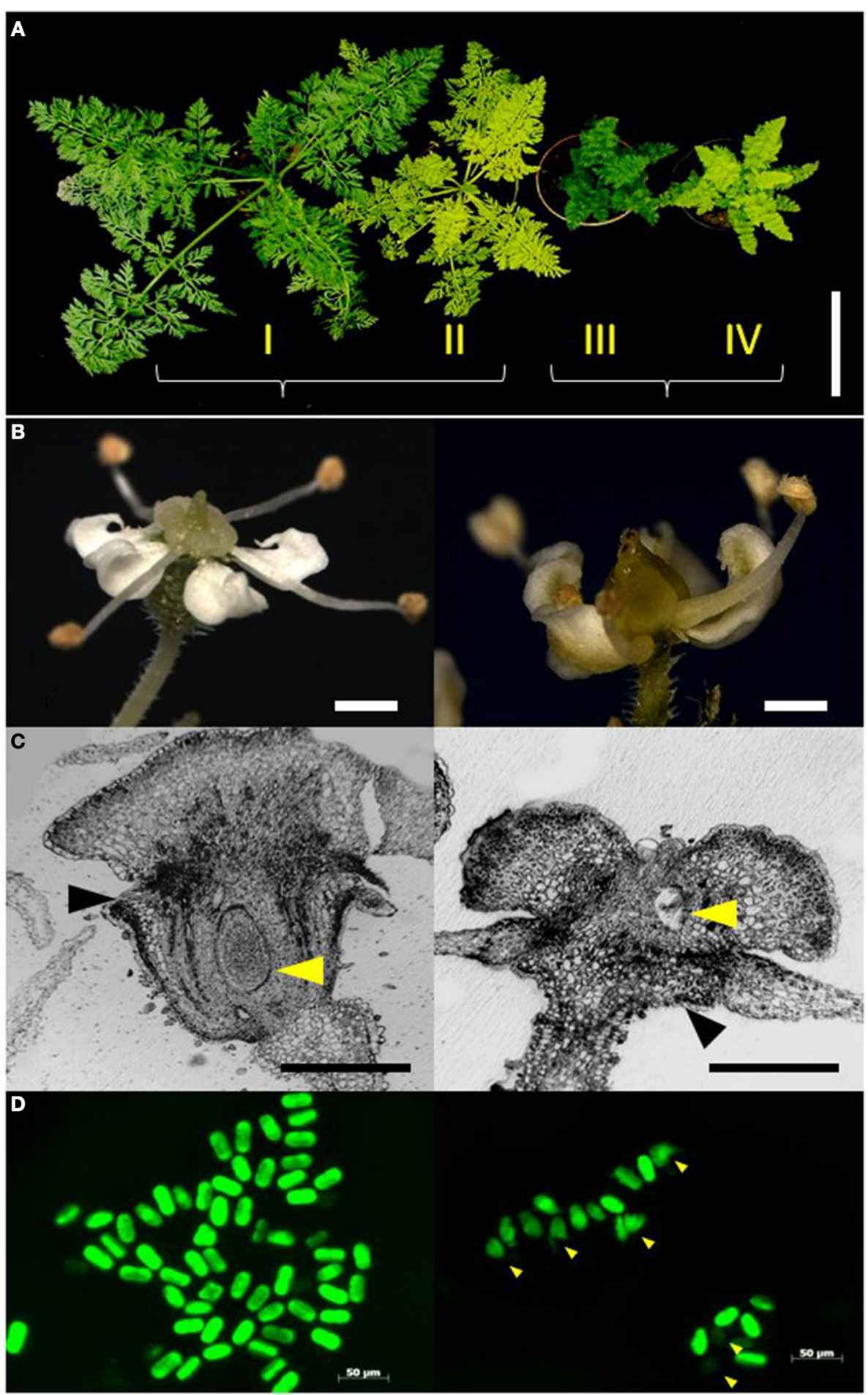

FIGURE 1 | Characterization of the phenotype classes. (A) Representative plants of the four phenotype classes I-IV in the $F_{2}$ segregating population DM19 obtained from a cross between mutants yel and cola. From left to right: wild-type plant with green and normal leaf structure (I); yel-mutant (II); cola-mutant (III); yel/cola double mutant (IV) (Bar $=10 \mathrm{~cm}$ ). (B) Morphology of reproductive organs. Left: epigynous flower of wild-type. Right: hypogynous flower of cola-mutant (Bars $=1.0 \mathrm{~mm}$ ). (C) Histo-morphological sections of flowers. Left: wild-type. Right: cola-mutant. Black arrowheads: petals, yellow arrowheads: ovule (Bars $=0.5 \mathrm{~mm}$ ). (D) FDA pollen staining. Fertile pollen grains revealed a intensive greenish stain, whereas sterile and undeveloped pollen grains were stained weakly; Left: wild-type, Right: cola-mutant, arrowheads indicate undeveloped microspores. 
least 400 pollen grains per plant were classified. The mean values of pollen analysis data were compared by Student's $t$-test at a significance level $p<0.05$.

\section{DNA EXTRACTION, RAPD-, DOUBLE PRIMER (dp)RAPD- AND AFLP-ANALYSIS}

Genomic DNA was extracted from $0.5 \mathrm{~g}$ of young leaf tissue from both parental lines and from $161 \mathrm{~F}_{2}$ plants of the DM19 population, using the method of Porebski et al. (1997). RAPD-PCR reactions were performed in $10 \mu \mathrm{l}$ volume containing $1 \mathrm{x}$ PCR buffer (InVitek, Berlin, Germany), $2.25 \mathrm{mM} \mathrm{MgCl}_{2}, 0.2 \mathrm{mM}$ dNTPs, $0.2 \mu \mathrm{M}$ arbitrary decamer primer (Roth $\mathrm{GmbH}$, Karlsruhe, Germany), 0.12 U InViTaq-polymerase (InVitek) and $8 \mathrm{ng}$ total plant DNA. The thermocycler (PT 200; Bio-Rad, Hercules, CA, USA) was programmed as follows: initial denaturation at $94^{\circ} \mathrm{C}$ for $2 \mathrm{~min}$; 45 cycles of $94^{\circ} \mathrm{C}$ for $1 \mathrm{~min}, 36^{\circ} \mathrm{C}$ for $1 \mathrm{~min}, 72^{\circ} \mathrm{C}$ for $2 \mathrm{~min}$ and final extension at $72^{\circ} \mathrm{C}$ for $7 \mathrm{~min}$. Amplification products were separated on $1 \%$ agarose gels using the $100 \mathrm{bp}$ ladder (Invitrogen, Carlsbad, CA, USA) for size determination. The generation of dpRAPD markers followed the protocol described by Budahn et al. (2008). AFLP reactions were performed according to the instructions of the AFLP ${ }^{\circledR}$ analysis system I kit (Invitrogen, Carlsbad, CA, USA). The amplification products were separated at $50^{\circ} \mathrm{C}$ and $100 \mathrm{~W}$ for $3.5 \mathrm{~h}$ on $4 \%$ denaturating polyacrylamide gels (Sequigen GT; $38 \times 50 \mathrm{~cm}$; Bio-Rad Laboratories, Hercules, CA, USA) followed by silver staining according to Bassam et al. (1991). Fragment sizes were estimated using the 123 bp DNAladder and the 1D-phoretix-Software 5.2 (Biostep, G, Nonlinear Dynamics Ltd., Newcastle, UK). Only unambiguous and polymorphic fragments were scored. The designation of the RAPD markers contained the used decamer primer sequence and, the AFLP markers the applied EcoRI- and MseI-primers added by the estimated fragment sizes.

\section{SSR MARKERS}

The original primers and amplification conditions were described by Cavagnaro et al. (2011). A universal fluorescent labeling strategy was used, as described by Schuelke (2000). The unlabeled forward primer extended at the $5^{\prime}$ end by the 19 bp M13 sequence was combined with the original reverse primer and the fluorescently labeled M13 universal primer. The amplification products of two independent reactions with IRDye700 and IRDye800 labeled M13 primers were mixed. DNA fragments were separated on $6.5 \%$ polyacrylamide gels followed by fragment detection using a LI-COR 4300 automatic sequencer (LI-COR Biosciences, Lincoln, NE, USA). The fragment sizes were calculated by IRDye700 and IRDye800 labeled $50-350$ or $50-700$ bp size ladders, respectively. SSR markers of the DCM series (Niemann, 2001) were amplified, separated on the Sequigen GT system (Bio-Rad Laboratories, Hercules, CA, USA) and visualized by silver-staining. Primer sequences and annealing temperatures were summarized in Table S1.

\section{td MARKERS}

The primer sequences and amplification conditions have been described by Grzebelus et al. (2007). Ten primer combinations were selected for the analysis. The amplification products were separated on $4.5 \%$ polyacrylamide gels and visualized by silver staining (Bassam et al., 1991).

\section{GENE-SPECIFIC MARKERS}

MADS-box genes of the carrot have been identified after generation of a cDNA library from wild-type carrot flowers (Linke et al., 2003). Additional sequences of genes with expected roles during reproductive organ differentiation and pollen development in the carrot were selected from NCBI database (complete list in Table S1; short list in Table 1). Gene-specific primers for PCR and mapping analyses were generated in the frame of earlier work (Linke et al., 2003; Campos et al., 2009; Cardoso et al., 2009; Grzebelus, pers. commun.). The deduced primer pairs have been tested for their specify by expression analyses. In all cases, fragments of the expected sizes were obtained. Gene-specificity of the primers was further confirmed by the use of nested primers or additional primer combinations. Regarding different isoforms ( $A O X$ genes) and domain-derived sequence similarities (MADS-box genes), further analysis was performed by sequenceanalyses [direct sequencing of PCR fragments obtained from cDNA (MADS-box genes)] or at least by internal PCR-tests with nested primers to ensure a clear differentiation between similar sequences. Flower-specific expression during different developmental stages was analyzed in wild-type carrot plants by RT-PCR or by in situ hybridization of mRNA (MADS-box genes, Linke et al., 2003; AOX genes, Campos et al., 2009).

The different primer pairs were tested for DNA polymorphisms in the cola- and the yel-parent and in selected progeny plants. PCR amplification products were separated on $1 \%$ agarose gels and visualized by ethidium bromide staining. Only primer pairs, providing clear polymorphisms, were used in the segregating $\mathrm{F}_{2}$ population DM19. Primers and amplification conditions were summarized in Table 1. Primers for amplification of DcMADS3 were deduced from NCBI accession number AJ271149. The forward primer binds at the nucleotide positions 114-132 within the MADS-domain. The reverse primer was deduced from the nucleotide positions 653 to 637 that encompassed the last ten amino acids of the coding sequence. For amplification of DcMADS5, the forward primer was deduced from the K-box region (LGTK-tag; positions 357-376). The reverse primer binds to the nucleotides 739-720 and was deduced from the PGWML-motif consisting of the five penultimate amino acids preceding the terminus of the predicted protein that reveal similarities within the SEPALLATA1-group of MADSbox genes. For both of the MADS-box genes, unique fragments were obtained that have been classified by PCR-sequencing previously (Linke et al., 2003). The forward primer for amplification of DcAOX2a was deduced from the nucleotide positions 539 to 559 of the mRNA-derived cDNA of the mitochondrial alternative oxidase 2a (accession number EU286575.2) in the ferritin-likediiron-binding region. The reverse primer encompassed positions 1275-1252 and derived from the $3^{\prime}$-UTR region. Two alleles of DcAOX $2 a$ were known, the L-allele, consisting of 5263 bp (accession number GQ248714) and the S-allele consisting of $4977 \mathrm{bp}$ (accession number GQ248713). Using the described primer set, an L-allele specific fragment of $1930 \mathrm{bp}$ and a S-allele specific fragment of 1654 bp where intron 3 varied in size between 1226 and 


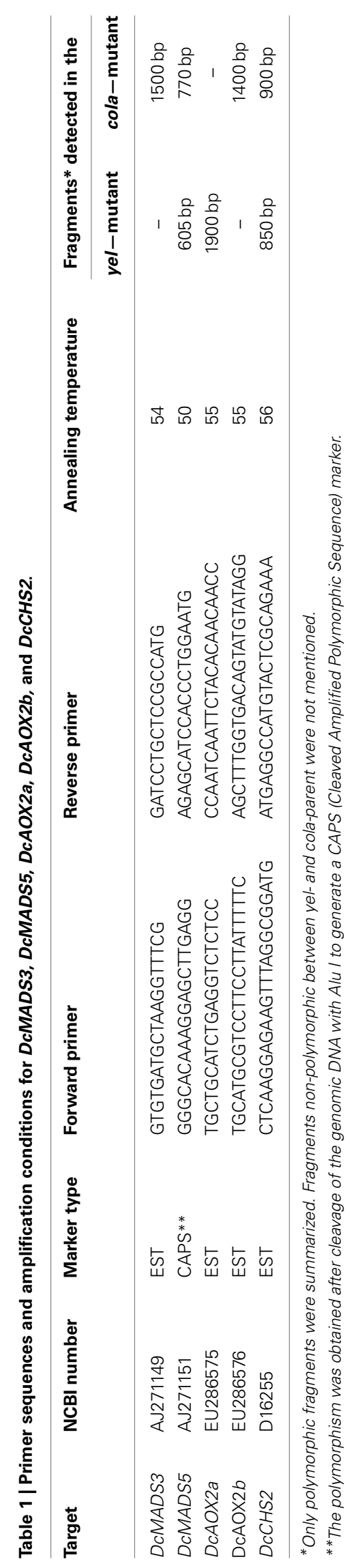

$941 \mathrm{bp}$ has been characterized (Cardoso et al., 2009). The same gene-specific fragments were also used for analyses of the present mapping population to include these pre-characterized polymorphisms into our yet more extended linkage map. As was shown by Cardoso et al. (2009), the complete gene sequence of DcAOX2b, including exons and introns, consisted of $1958 \mathrm{bp}$. The size of the introns have been assigned to 822 (intron 1), 91 (intron 2), and 85 (intron 3). The length of the deduced mRNA sequence was stated as $1267 \mathrm{bp}$. For the amplification of $D c A O X 2 b$ we have used primers published by Campos et al. (2009), that covers the nucleotide positions 1-23 (forward primer) of the carrot mitochondrial alternative oxidase $2 b$ (accession number EU286576). The reverse primer was deduced from positions 770 to 747 . Forward and reverse primers designed for the amplification of DcCHS2 were generated from an exon-intron-exon bridge, and were deduced from nucleotide positions 2583 to 2606 and 3484 to 3461 of the gDNA sequence D16255.1, respectively.

Non-polymorphic amplification products were digested with the restriction endonucleases AluI, HaeIII, RsaI, TaqI, BsmI, and Hinf I to identify recognition site polymorphisms and to develop CAPS markers by this way.

\section{DATA SCORING, LINKAGE ANALYSIS, AND MAP CONSTRUCTION}

The phenotypic and molecular data were formated as required for JoinMap version 4.0 (Van Ooijen, 2006). AFLP-, RAPD-, and dpRAPD-markers were scored in a dominant and SSR-markers in a co-dominant manner. The $p$-value was calculated after chisquare-test for all markers. Linked loci were grouped using a LOD thresholds from 2.0 to 10.0 in steps of 0.2 and recombination frequency lower than 0.4. The jump threshold was set to 5.0 and the third mapping round was carried out. The recombination frequencies were converted to mapping distances (in $\mathrm{cM}$ ) using the Kosambi function.

\section{RESULTS}

\section{PHENOTYPE SEGREGATION}

A homozygous recessive cola-mutant plant was used to pollinate a homozygous recessive yel-mutant plant to generate the mapping population. All $\mathrm{F}_{1}$ plants expressed the wild-type phenotype (green leaves and normal leaf shape). A total of 161 plants of the $\mathrm{F}_{2}$ progeny DM19 segregated into four distinct phenotype classes (Figure 1A). The class I plants represent the wild-type of the cultivated carrot. The phenotype class II is highly similar to the wildtype, but the chlorophyll biosynthesis is dramatically delayed resulting in yellowish leaves (yel—mutant). Compressed aboveground plant tissues resulting in a semi-dwarf phenotype are the characteristics of the class III plants (cola-mutant). Plants of the phenotype class IV showed the characters of both mutants, semi-dwarf plants with yellowish leaves. The visual characters of the roots (size, shape, and color) were not influenced for the different phenotype classes. There was no significant deviation from Mendelian inheritance observed (ratio 9:3:3:1) for two independent loci (Table 2). After vernalization $121 \mathrm{~F}_{2}$ plants $(75 \%)$ flowered within a 100 day period. All plants of the phenotype classes I and II $(n=98)$ developed epigynous flowers, whereas all cola-mutant associated plants (phenotype class III and IV; $n=23$ ) expressed hypogynous flowers (Table 2; Figures 1B,C). 
Table 2 | Phenotypical segregation of flower traits in the $F_{2}$ progeny DM19.

\begin{tabular}{lcllcc}
\hline $\begin{array}{l}\text { Phenotypic } \\
\text { class }\end{array}$ & $\begin{array}{l}\text { No. of } \\
\text { plants }^{\text {a }}\end{array}$ & $\begin{array}{l}\text { Observed } \\
\text { phenotype }\end{array}$ & $\begin{array}{l}\text { Putative } \\
\text { genotype }\end{array}$ & $\begin{array}{l}\text { Bolting } \\
\text { plants }^{\mathbf{b}}\end{array}$ & $\begin{array}{c}\text { Flower development } \\
\text { epigynous/hypogynous }\end{array}$ \\
\hline I & 90 & Green / normal leaves & YEL. / COLA. & $77(86 \%)$ & $77 / 0$ \\
II & 32 & Yellow / normal leaves & yel yel / COLA. & $21(66 \%)$ & $21 / 0$ \\
III & 31 & Green / cola leaves & YEL. / cola cola & $19(61 \%)$ & $0 / 17(2)^{\mathrm{c}}$ \\
IV & 8 & Yellow / cola leaves & yel yel / cola cola & $6(75 \%)$ & $0 / 6$ \\
\hline
\end{tabular}

${ }^{a}$ Fit for Mendelian digenic inheritance $\chi^{2}-(9: 3: 3: 1$, phenotype classes $)=0.56 ; p=0.91$.

${ }^{b}$ Fit for Mendelian monogenic inheritance $\chi^{2}-(3: 1$, Bolting: non bolting) $=0.68 ; p=0.40$; Ratio of bolting plants in the cola classes (III+IV) was significantly lower $(64 \%, p=0.001)$ than in the WT (COLA) classes (I+II) with $80 \%$.

This suggested a potential association to the cola mutant, but a verification by testing of a larger progeny is required;

${ }^{c}$ Two plants expressed partially both types of flowers.

Table 3 | Microspore characteristics of the cola-mutant in comparison to the wild-type.

\begin{tabular}{|c|c|c|c|c|c|}
\hline \multirow[t]{2}{*}{ Flower type } & \multirow[t]{2}{*}{$n$} & \multirow{2}{*}{$\begin{array}{l}\text { Pollen viability }{ }^{\mathrm{a}}(\%) \\
\quad \text { Mean } \pm S D\end{array}$} & \multirow{2}{*}{$\begin{array}{c}S+U \text { Pollen }^{\mathrm{b}}(\%) \\
\text { Mean } \pm S D\end{array}$} & \multicolumn{2}{|c|}{ Size of viable microspores ${ }^{c}$} \\
\hline & & & & Mean $\pm S D$ & Mean $\pm S D$ \\
\hline Wild-type (epigynous) & 10 & $68.67 \pm 6.89 \mathrm{a}$ & $1.36 \pm 2.05 a$ & $32.4 \pm 5.1 \mathrm{a}$ & $16.2 \pm 3.1 \mathrm{a}$ \\
\hline cola-mutant (hypogynous) & 10 & $49.88 \pm 14.75 b$ & $9.16 \pm 5.67 b$ & $28.3 \pm 4.2 b$ & $15.5 \pm 3.2 \mathrm{a}$ \\
\hline
\end{tabular}

Reduced pollen viability was observed in cola-mutant plants in comparison to the wild-type plants (49.9 and 68.7\%, respectively). The proportion of small and undeveloped pollen grains was much higher and also the viable pollen grains were significantly smaller than those of the wild type flowers (Table 3; Figure 1D).

\section{LINKAGE ANALYSIS}

After a pre-screening experiment using the parental plants, 21 RAPD primers, 2 dpRAPD, 28 AFLP, and 7 td primer combinations were chosen for the analysis of the segregating population. In total, 319 markers were polymorphic between the parents of DM19 and were used for map construction (Table 4). Nine major groups encompassing 285 markers were generated. The resulting carrot linkage map (Figure 2) had a total length of $781 \mathrm{cM}$. The number of markers per LG ranged from 18 to 45 . The largest minor group, not connected with one of the nine major groups, contained five markers. LG-1 was the largest LG with $145 \mathrm{cM}$, while LG-7 was the shortest with $66 \mathrm{cM}$. The average distance between two neighboring markers was $2.7 \mathrm{cM}$.

\section{ASSIGNMENT OF LINKAGE GROUPS TO THE REFERENCE MAP}

The use of SSR and SCAR markers enabled the LGs of our carrot map to be assigned to the LGs of two reference maps. The original LG names were proposed by Iovene et al. (2011) and we assigned four markers (DcOR, Y2mark, Q1/800, and SSRN6W93) anchored in their physical carrot map. The LG names were adopted by Cavagnaro et al. (2011) and we were able to
Table 4 | Summary of mapped markers for the nine linkage groups of the carrot map.

\begin{tabular}{lccccccc}
\hline Marker & AFLP & $\begin{array}{c}\text { RAPD/ } \\
\text { dpRAPD }\end{array}$ & td & SSR & $\begin{array}{c}\text { EST/ } \\
\text { SCAR }\end{array}$ & $\begin{array}{c}\text { Mapped } \\
\text { traits }\end{array}$ & Total \\
\hline $\begin{array}{l}\text { Polymorphic } \\
\text { mapped }\end{array}$ & 216 & 60 & 10 & 22 & 9 & 2 & 319 \\
\hline LG-1 & 198 & 45 & 9 & 22 & 9 & 2 & 285 \\
LG-2 & 28 & 6 & 2 & 3 & 0 & YEL & 40 \\
LG-3 & 36 & 3 & 3 & 1 & 0 & 0 & 43 \\
LG-4 & 30 & 5 & 0 & 2 & 1 & 0 & 38 \\
LG-5 & 27 & 2 & 1 & 2 & 1 & COLA & 34 \\
LG-6 & 11 & 4 & 1 & 1 & 1 & 0 & 18 \\
LG-7 & 20 & 8 & 1 & 2 & 1 & 0 & 32 \\
LG-8 & 11 & 6 & 1 & 2 & 2 & 0 & 22 \\
LG-9 & 22 & 6 & 0 & 2 & 1 & 0 & 31 \\
\hline
\end{tabular}

map 15 SSRs from LGs 1-9. Two additional SSR markers (gSSR91 and gSSR138) were allocated by Alessandro et al. (2013). The distribution of these 21 markers was generally consistent with the reference maps. Mapping of two or more markers in each LG allowed drawing of seven LGs in the orientation corresponding to that applied by the authors of the reference maps with short/long chromosome arms in the North/South orientation. The orientation of LG-2 and LG-5 remained ambiguous, as each of them was anchored only by one reference marker. Marker 


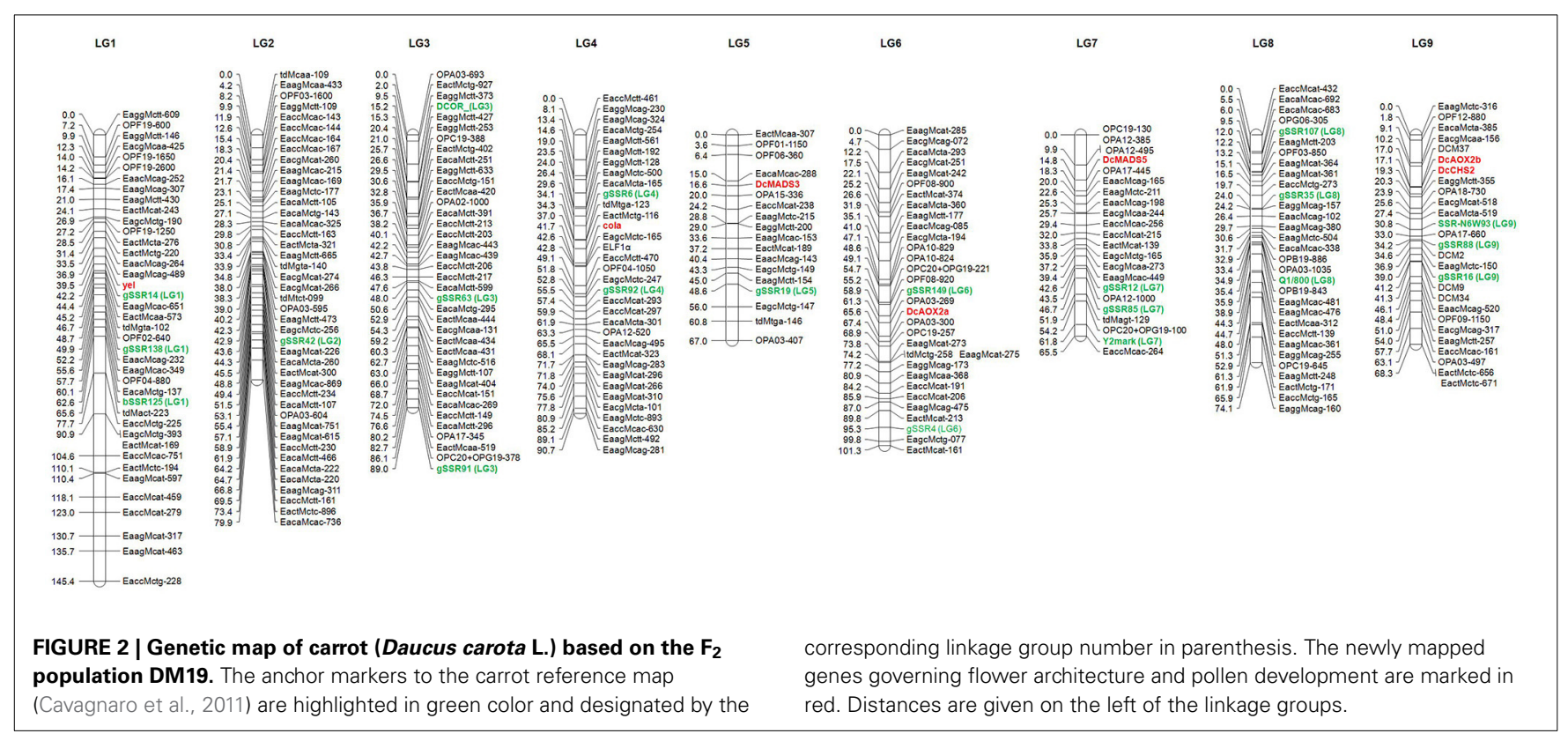

gSSR138 was found to be located in our map between gSSR14 and bSSR 125 and not distal from gSSR 14 as shown by Alessandro et al. (2013).

\section{MAPPING GENES RESPONSIBLE FOR FLOWERING TRAITS}

The COLA-locus was mapped successfully on LG-4 and the YEL-locus on LG-1 of the carrot map. To analyze, whether the flower-specific cola-mutant reveal any relationship to one of the flower-specific genes, known to play a prominent role for reproductive organ differentiation and pollen development (Gene-Specific Markers and Table 1), our aim was their preliminary assignment to appropriate LGs. Therefore, we have searched for polymorphisms between the parents of our mapping population. Although phenotypic segregation and our genetic data (compare to PHENOTYPE SEGREGATION) did not favor any association, we have included the data obtained. We have identified sequence polymorphisms for DcMADS3 and DcMADS5 as well as DcAOX2a, DcAOX2b, and DcCHS2 (Table 1) and mapped them to search for co-localization with the COLA-gene.

All of the analyzed gene-fragments revealed a different distribution than the COLA-locus, which indicated that there were no associations to the flower-specific defect that has been described here. DcMADS3 belonging to the B-class of homeotic genes was assigned to LG-5 and DcMADS5, a predicted member of the SEPALLATA-group of MADS-box genes, was mapped after cleavage of the amplification product with $A l u$ I to LG-7. For DcAOX2a a polymorphism was found concerning presence/absence of the fragment specific for the L-allele which was used successfully to assign it to LG-6. In our mapping analyses the polymorphism associated with $D c A O X 2 b$ was assigned to LG-9 indicating a different localization than the DcAOX2a sequence.

For the CHS gene, the lenght of the obtained fragment polymorphisms corresponded with the predicted size deduced from the genomic sequence of CHS2 in the cola-parent (900 bp), whereas the fragment-length was slightly shortenend in the yel-mutant (850 bp).

Despite of this tentative assignment, future work demands a more detailed analysis. Fine-mapping is still required to assign precisely the allelic state and yet undetected potential differences of intron-sizes, like InDels of smaller sizes that could not have been matched in this initial map. For example, a tool for subfamily grouping of the large $A O X$ family has been developed, where classification (or re-classification) of $A O X$-subfamily members by specific sequence-features was facilitated (Costa et al., 2014). In summary, all of the five proven genes did not co-segegate with the cola-associated flower defects we mentioned in this publication.

\section{DISCUSSION}

To date, a complete carrot genome sequence was not yet available, thus well-saturated genetic linkage maps are of essential relevance for successful carrot breeding and breeding research. Cavagnaro et al. (2011) have developed a linkage map containing 55 SSR markers, offering an important tool for further integration of molecular markers and gene-specific sequences of carrot. Currently, mapping of genes governing traits of economical relevance (e.g., flavors, volatiles and bioactive compounds) in individual well-characterized populations segregating for genespecific markers is under investigation (Nothnagel, pers. commun.). However, SSR markers offer a useful tool to integrate the results into a consensus map. The total length of the carrot map presented in this work was $781 \mathrm{cM}$, compared to 669 cM of the map shown by Alessandro et al. (2013), Just et al. (2007), and Cavagnaro et al. (2011) earlier published separated maternal and paternal maps with a total length between 1050 and $1273 \mathrm{cM}$. The marker density of our map was nearly as high as that presented by Alessandro et al. (2013) and the largest gap was $14 \mathrm{cM}$. Using SSRs as anchor markers, the LGs of our carrot map matched exactly to the LGs of the reference maps. For seven of the nine LGs at least two anchor markers were allocated 
enabling us to determine the orientation of the LGs in comparison to the reference maps. Thus, we showed that 21 markers included in the reference maps were suitable for linkage analysis performed on the DM19 population. The carrot populations used for map generation by Cavagnaro et al. (2011), Alessandro et al. (2013) and our group were unrelated and had different pedigrees. Therefore the defined marker set is of fundamental importance for independent mapping projects, as it facilitates the creation of a consensus map.

The cola-mutation revealed a compact leaf-habit and a semidwarf phenotype that is associated to a reduced cell elongation. Moreover, flowering traits were also affected including an impaired transition to flowering, and abnormal flower architecture with partial male sterility (Nothnagel et al., 2005, this study). The phenotype was inherited in a monogenic recessive fashion causing hypogynous flowers in homozygous state which could be clearly distinguished from epigynous flowers of the wild-type. Additionally, the distorted anther development resulted in lower pollen viability probably due to an impaired development of the sporophytic tissue that surrounded the pollen chambers. The COLA-locus was mapped on LG-4.

Although phenotype classification and genetic segregation did not favor the hypothesis, that the COLA-locus is related to one of the obtained polymorphisms derived from flower-specific sequences, we have included several of the obtained polymorphisms into our map regarding future aims to extend analyses on flower- and reproductive genes in the carrot. The initiation of flowering and the patterning of floral primordia into discrete domains that give rise to different types of floral organs have been well investigated in model plants. Flower development depends on a complex gene regulation network (Immink et al., 2010; Liu and Mara, 2010). Most of the participating genes encode for transcription factors involved in the regulation of gene expression in a strictly hierarchical manner. A vast majority of the central regulating genes belong to the MADS-box family. Carrot MADS-box genes DcMADS3 and DcMADS5 belong to the B-class and E-class MADS-box genes specifying the identity of stamens and hence, the development of anthers and pollen. DcMADS3 likely plays a similar role in Daucus as shown for Arabidopsis and Antirrhinum. This was supported by the fact that DcMADS3 was down-regulated in homeotic flowers of the carpeloid CMS type of carrot where stamens were completely replaced by carpels (Linke et al., 2003). For DcMADS5, a significant sequence similarity to SEPALLATA1 group and a continuous expression throughout flower development supported the hypothesis that the SEP1 gene was required from early stages of floral development onwards to mediate activities especially of the B- and C-organ identity genes (Flanagan and Ma, 1994; Pelaz et al., 2000; Honma and Goto, 2001). In the present work, the two carrot MADS-box sequences DcMADS3 and DcMADS5 were assigned to LG-5 and LG-7, respectively.

Campos et al. (2009) have shown differential expression of $D c A O X 1$ and DcAOX2 genes at early stages of floral organ formation. As reported by Cardoso et al. (2009), AOX2a was successfully analyzed in a preliminary mapping approach of the DM19 population. In the present work, obtained polymorphisms for $A O X 2 a$ and $A O X 2 b$ were assigned to the LGs LG-6 and LG-9, respectively.
Taylor and Jorgensen (1992) demonstrated that the development of the male gametophyte essentially required flavonoid biosynthesis. Hence, CHS deficient plants (with so-called white pollen) were self-incompatible. Pollen germination on the stigmata could be restored when a small amount of kaempherol was provided (Mo et al., 1992). In this study, a CHS sequence of $D$. carota was assigned to LG-9.

In conclusion, a well-saturated map of carrot was developed. The cola-locus, associated to advanced defects of male and female organ differentiation was associated to LG-4 and revelaed no cosegration with several markers for genes involved in flowering and reproduction. Hence, six loci significant for these processes were mapped to five LGs. Considering two other genes, Vrn1, responsible for early flowering habit and $R f 1$ restoring petaloid CMS, have been assigned by Alessandro et al. (2013) to LG-2 and LG-9, respectively, it can be assumed that eight loci associated with flower architecture and reproduction are dispersed to six out of nine carrot chromosomes. Indeed, fine-mapping of the identified loci will be required, especially regarding the growing number of subgroup members within the selected genefamilies that are not yet completely available in the database. Several tools for structural analyses of high diversity of gene families, like the compositions of the $A O X$ genes might facilitate a detailed analysis also in non-model plants (Costa et al., 2014).

Finally, the use of anchor markers that exclusively derived from the American gene pool, enables the generation of the first integrated carrot map based on markers of both, the European and American carrot gene pool. This opens advanced options for the establishment of a comprehensive consensus map by co-operative activities between the research groups working on carrot genetics. Furthermore, the addition of gene-derived markers to the present map may provide a good starting point for comparative mapping in other Apiaceae species like Apium, Petrosellinum, Carum, or Foeniculum for which Daucus can serve as well-characterized representative. This might facilitate the future research on genes associated with traits important for both, food and non-food sector (Barańska et al., 2005; Ulrich et al., 2011) and allows the identification of genes with general interest for Apiaceae species.

\section{AUTHOR CONTRIBUTIONS}

Holger Budahn: SSR analysis and map construction. Rafał Barański: AFLP and SSR analysis. Dariusz Grzebelus: td analysis. Agnieszka Kiełkowska: RAPD and AFLP analysis. Petra Straka: RAPD and AFLP analysis. Kai Metge: RAPD and AFLP analysis. Bettina Linke: Primer design MADS-box genes, PCR-analyses of parental plants of the mapping population, substantial contributions to conception and design of the manuscript. Thomas Nothnagel: Generation of the mapping population, flower morphology, histological analysis, substantial contributions to conception and design of the manuscript.

\section{FUNDING}

Parts of this work were supported by a bilateral cooperation project of BMELV (Germany) and MNiSW (Poland, project DS3500/KGHN granted to the Univ. of Agric. in Krakow). 


\section{ACKNOWLEDGMENTS}

Authors acknowledge Gudrun Schwenk, Erika Krebs, Cornelia Freyer, and Karla Müller for the excellent technical assistance.

\section{SUPPLEMENTARY MATERIAL}

The Supplementary Material for this article can be found online at: http://www.frontiersin.org/journal/10.3389/fpls.2014.00504/ abstract

\section{REFERENCES}

Affourtit, C., Albury, M. S., Crichton, P. G., and Moore, A. L. (2002). Exploring the molecular nature of alternative oxidase regulation and catalysis. FEBS Lett. 510, 121-126. doi: 10.1016/S0014-5793(01)03261-6

Ageez, A., Kazama, Y., Sugiyama, R., and Kawano, S. (2005). Male-fertility genes expressed in male flower buds of Silene latifolia include homologs of antherspecific genes. Genes Genet. Syst. 80, 403-413. doi: 10.1266/ggs.80.403

Alessandro, M. S., Galmarini, C. R., Iorizzo, M., and Simon, P. W. (2013). Molecular mapping of vernalization requirement and fertility restoration genes in carrot. Theor. Appl. Genet. 126, 415-423. doi: 10.1007/s00122-012-1989-1

Atanassov, I., Russinova, E., Antonov, L., and Atanassov, A. (1998). Expression of an anther-specific chalcone synthase-like gene is correlated with uninucleate microspore development in Nicotiana sylvestris. Plant Mol. Biol. 38, 1169-1178.

Barańska, M., Schulz, H., Barański, R., Nothnagel, T., and Christensen, L. P. (2005). In situ simultaneous analysis of polyacetylenes, carotenoids and polysaccharides in carrot roots. J. Agric. Food Chem. 53, 6565-6571. doi: 10.1021/jf05 10440

Barański, R., Maksylewicz-Kaul, A., Nothnagel, T., Cavagnaro, P. F., Simon, P. W., and Grzebelus, D. (2012). Genetic diversity of carrot (Daucus carota L.) cultivars revealed by analysis of SSR loci. Genet. Resour. Crop Evol. 59, 163-170. doi: 10.1007/s10722-011-9777-3

Bassam, B. J., Caetano-Anolles, G., and Gresshoff, P. M. (1991). Fast and sensitive silver staining of DNA in polyacrylamide gels. Appl. Biochem. Biotech. 42, 181-188.

Becker, A., and Theissen, G. (2003). The major clades of MADS-box genes and their role in the development and evolution of flowering plants. Mol. Phylogenet. Evol. 29, 464-489. doi: 10.1016/S1055-7903(03)00207-0

Brachi, B., Morris, G. P., and Borevitz, J. O. (2011). Genome-wide association studies in plants: The missing heritability is in the field. Genome Biol. 12:232. doi: 10.1186/gb-2011-12-10-232

Brandeen, J. M., and Simon, P. W. (2007). "Carrot," in Genome Mapping and Molecular Breeding in Plants, Vegetables, ed C. Kole (Berlin; Heidelberg: Springer-Verlag), 161-184.

Budahn, H., Schrader, O., and Peterka, H. (2008). Development of a complete set of disomic rape-radish chromosome addition lines. Euphytica 162, 117-128. doi: 10.1007/s10681-007-9609-x

Campos, M. D., Cardoso, H. G., Linke, B., Costa, J. H., de Melo, D. F., Justo, L., et al. (2009). Differential expression and co-regulation of carrot AOX genes (Daucus carota). Physiol. Plant. 137, 578-591. doi: 10.1111/j.1399-3054.2009.01282.x

Cardoso, H. G., Campos, M. D., Costa, J. H., Campos, M. C., Nothnagel, T., and Arnholdt-Schmitt, B. (2009). Carrot alternative oxidase gene AOX2a demonstrates allelic and genotypic polymorphisms in intron 3. Physiol. Plant. 137, 592-608. doi: 10.1111/j.1399-3054.2009.01299.x

Cavagnaro, P. F., Chung, S. M., Manin, S., Yildiz, M., Ali, A., Alessandro, M. S., et al. (2011). Microsatellite isolation and marker development in carrot - genomic distribution, linkage mapping, genetic diversity analysis and marker transferability across Apiaceae. BMC Genomics 12:386. doi: 10.1186/1471-2164-12-386

Cavagnaro, P. F., Chung, S. M., Szklarczyk, M., Grzebelus, D., Senalik, D., Atkins, A. E., et al. (2009). Characterization of a deep-coverage carrot (Daucus carota L.) BAC library and initial analysis of BAC-end sequences. Mol. Genet. Genomics 281, 273-288. doi: 10.1007/s00438-008-0411-9

Chai, T. T., Colmer, T. D., and Finnegan, P. M. (2010). Alternative oxidase, a determinant of plant gametophyte fitness and fecundity. Plant Signal Behav. 5, 604-606. doi: 10.4161/psb.11502

Clotault, J., Geoffriau, E., Linneton, E., Briard, M., and Peltier, D. (2010). Carotenoid biosynthesis genes provide evidence of geographical subdivision and extensive linkage disequilibrium in carrot. Theor. Appl. Genet. 121, 659-672. doi: 10.1007/s00122-010-1338-1
Coen, E. S., and Meyerowitz, E. M. (1991). The war of the whorls: genetic interactions controlling flower development. Nature 353, 31-37.

Costa, J. H., McDonald, A. E., Arnhold-Schmitt, B., and Fernandes de Melo, D. (2014). A classification scheme for alternative oxidases reveals the taxonomic distribution and evolutionary history of the enzyme in angiosperms. Mitochondrion. doi: 10.1016/j.mito.2014.04.007. [Epub ahead of print].

Djajanegara, I., Finnegan, P. M., Mathieu, C., McCabe, T., Whelan, J., and Day, D. A. (2002). Regulation of alternative oxidase gene expression in soybean. Plant Mol. Biol. 50, 735-742. doi: 10.1023/A:1019942720636

Dobritsa, A. A., Lei, Z., Nishikawa, S., Urbanczyk-Wochniak, E., Huhman, D. V., Preuss, D., et al. (2010). LAP5 and LAP6 encode anther-specific proteins with similarity to chalcone synthase essential for pollen exine development in Arabidopsis. Plant Physiol. 153, 937-955. doi: 10.1104/pp.110.157446

Finnegan, P. M., Whelan, J., Millar, A. H., Zhang, Q. S., Smith, M. K., Wiskich, J. T., et al. (1997). Differential expression of the multigene family encoding the soybean mitochondrial alternative oxidase. Plant Physiol. 114, 455-466.

Flanagan, C. A., and Ma, H. (1994). Spatially and temporally regulated expression of the MADS-box gene AGL2 in wild-type and mutant Arabidopsis flowers. Plant Mol. Biol. 26, 581-595.

Grzebelus, D., Iorizzo, M., Senalik, D., Ellison, S., Cavagnaro, P., Macko-Podgorni, A., et al. (2014). Diversity, genetic mapping, and signatures of domestication in the carrot (Daucus carota L.) genome, as revealed by diversity arrays technology (DArT) markers. Mol. Breed. 33, 625-637. doi: 10.1007/s11032-013-9979-9

Grzebelus, D., Jagosz, B., and Simon, P. W. (2007). The DcMaster transposon display maps polymorphic insertion sites in the carrot (Daucus carota L.) genome. Gene 390, 67-74. doi: 10.1016/j.gene.2006.07.041

Heslop-Harrison, J., and Heslop-Harrison, Y. (1970). Evaluation of pollen viability by enzymatically induced fluorescence: intracellular hydrolysis of fluoresceine diacetate. Stain Technol. 45, 115-120.

Honma, T., and Goto, K. (2001). Complexes of MADS-box proteins are sufficient to convert leaves into floral organs. Nature 409, 525-529. doi: 10.1038/35054083

Immink, R. G., Kaufmann, K., and Angenent, G. C. (2010). The 'ABC' of MADS domain protein behaviour and interactions. Semin. Cell Dev. Biol. 21, 87-93. doi: 10.1016/j.semcdb.2009.10.004

Iorizzo, M., Senalik, D. A., Grzebelus, D., Bowman, M., Cavagnaro, P. F., Matvienko, M., et al. (2011). De novo assembly and characterization of the carrot transcriptome reveals novel genes, new markers, and genetic diversity. BMC Genomics 12:389. doi: 10.1186/1471-2164-12-389

Iovene, M., Cavagnaro, P. F., Senalik, D., Buell, C. R., Jiang, J., and Simon, P. W. (2011). Comparative FISH mapping of Daucus species (Apiaceae family). Chromosome Res. 19, 493-506. doi: 10.1007/s10577-011-9202-y

Just, B. J., Santos, C. A. F., Fonseka, M. E. N., Boiteux, L. S., Oloizia, B. B., and Simon, P. W. (2007). Carotenoid biosynthesis structural genes in carrot (Daucus carota): isolation, sequence-characterization, single nucleotide polymorphism (SNP) markers and genome mapping. Theor. Appl. Genet. 114, 693-704. doi: 10.1007/s00122-006-0469-x

Karpova, O. V., Kuzmin, E. V., Elthon, T. E., and Newton, K. J. (2002). Differential expression of alternative oxidase genes in maize mitochondrial mutants. Plant Cell 14, 3271-3284. doi: 10.1105/tpc.005603

Linke, B., Nothnagel, T., and Börner, T. (2003). Flower development in carrot CMS plants: mitochondria affect the expression of MADS box genes homologous to GLOBOSA and DEFICIENS. Plant J. 34, 27-37. doi: 10.1046/j.1365313X.2003.01703.x

Liu, Z., and Mara, C. (2010). Regulatory mechanisms for floral homeotic expression. Semin. Cell Dev. Biol. 21, 80-86. doi: 10.1016/j.semcdb.2009.11.012

Macko, A., and Grzebelus, D. (2008). DcMaster transposon display as a tool for diversity evaluation of carrot breeding materials and for hybrid seed purity testing. J. Appl. Genet. 49, 33-39. doi: 10.1007/BF03195246

Mo, Y., Nagel, C., and Taylor, L. P. (1992). Biochemical complementation of chalcone synthase mutants defines a role for flavonols in functional pollen. Proc. Natl. Acad. Sci. U.S.A. 89, 7213-7217.

Niemann, M. (2001). Entwicklung von Mikrosatelliten Markern bei der Möhre (Daucus carota L.) und die Markierung eines Alternaria-Resistenzgens. Dissertation, University Hannover. Shaker Verlag, Aachen.

Niemann, M., Westphal, L., and Wricke, G. (1997). Analysis of microsatellite markers in carrot (Daucus carota L. sativus). J. Appl. Genet. 38A, 20-27.

Nothnagel, T., Ahne, R., and Straka, P. (2005). Morphology, inheritance and mapping of a compressed lamina mutant of carrot. Plant Breed. 124, 481-486. doi: 10.1111/j.1439-0523.2005.01154.x 
Nothnagel, T., and Straka, P. (2003). Inheritance and mapping of a yellow leaf mutant of carrot (Daucus carota). Plant Breed. 122, 339-342. doi: 10.1046/j.1439-0523.2003.00884.x

Parenicova, L., de Folter, S., Kieffer, M., Horner, D. S., Favalli, C., Busscher, J., et al. (2003). Molecular and phylogenetic analyses of the complete MADS-box transcription factor family in Arabidopsis: new openings to the MADS world. Plant Cell 15, 1538-1551. doi: 10.1105/tpc.011544

Pelaz, S., Ditta, G. S., Baumann, E., Wisman, E., and Yanofsky, M. F. (2000). B and $\mathrm{C}$ floral identity functions require SEPALLATA MADS-box genes. Nature 405, 200-203. doi: 10.1038/35012103

Porebski, S., Bailey, L. G., and Baum, B. R. (1997). Modification of a CTAB DNA extraction protocol for plants containing high polysaccharide and polyphenol components. Plant Mol. Biol. Rep. 15, 8-15.

Rong, J., Janson, S., Umehara, M., Ono, M., and Vrieling, K. (2010). Historical and contemporary gene dispersal in wild carrot (Daucus carota ssp. carota) populations. Ann. Bot. 106, 285-296. doi: 10.1093/aob/mcq108

Schrader, O., Ahne, R., and Fuchs, J. (2003). Karyotype analysis of Daucus carota L. using Giemsa C-Banding and FISH of 5 S and 18S/25S rRNA specific genes. Caryologia 56, 149-154. doi: 10.1080/00087114.2003.10589318

Schuelke, M. (2000). An economic method for the fluorescent labeling of PCR fragments. Nat. Biotechnol. 18, 233-234. doi: 10.1038/72708

Schwarz-Sommer, Z., Huijser, P., Nacken, W., Saedler, H., and Sommer, H. (1990). Genetic control of flower development by homeotic genes in Antirrhinum majus. Science 250, 931-936.

Simon, P. W., Freeman, R., Vieira, J. V., Boiteux, L. S., Briard, M., Nothnagel, T., et al. (2008). "Carrot," in Handbook of Plant Breeding, Vegetables II, eds J. Prohens and F. Nuez (New York, NY: Springer), 327-357.

Simon, P. W., Pollak, L. M., Clevidence, B. A., Holden, J. M., and Haytowitz, D. B. (2009). Plant breeding for human nutritional quality. Plant Breed. Rev. 31, 325-415. doi: 10.1002/9780470593783.ch7

Taylor, L. P., and Jorgensen, R. (1992). Conditional male fertility in chalcone synthase-deficient petunia. J. Hered. 83, 11-17.

Theissen, G. (2001). Development of floral organ identity: stories from the MADS house. Curr. Opin. Plant Biol. 4, 75-85. doi: 10.1016/S1369-5266(00)00139-4

Ulrich, D., Bruchmüller, T., Krüger, H., and Marthe, F. (2011). Sensory characteristics and volatile profiles of Parsley (Petroselinum crispum [Mill.] Nym.) in correlation to resistance properties against Septoria Blight (Septoria petroselini). J. Agric. Food Chem. 59, 10651-10656. doi: 10.1021/jf202120d
Umehara, M., Eguchi, I., Kaneko, D., Ono, M., and Kamada, H. (2005). Evaluation of gene flow and its environmental effects in the field. Plant Biotechol. 22, 497-504. doi: 10.5511/22.497

van der Meer, I. M., Stam, M. E., van Tunen, A. J., Mol, J. N. M., and Stuitje, A. R. (1992). Antisense inhibition of flavonoid biosynthesis in petunia anthers results in male sterility. Plant Cell 4, 253-262.

Van Ooijen, J. W. (2006). Join Map ${ }^{\circledR} 4$, Software for the Calculation of Genetic Maps in Experimental Populations. Wageningen: Kyazma BV.

Walden, A. R., Walter, C., and Gardner, R. C. (1999). Genes expressed in Pinus radiata male cones include homologs to anther-specific and pathogen response genes. Plant Physiol. 121, 1103-1116.

Yang, S., Terachi, T., and Yamagishi, H. (2008). Inhibition of chalcone synthase expression in anthers of Raphanus sativus with Ogura male sterile cytoplasm. Ann. Bot. 102, 483-489. doi: 10.1093/aob/mcn116

Yildiz, M., Willis, D. K., Cavagnaro, P. F., Iorizzo, M., Abak, K., and Simon, P. W. (2013). Expression and mapping of anthocyanin biosynthesis genes in carrot. Theor. Appl. Genet. 126, 1689-1702. doi: 10.1007/s00122-013-2084-y

Conflict of Interest Statement: The authors declare that the research was conducted in the absence of any commercial or financial relationships that could be construed as a potential conflict of interest. Furthermore, we declare that the experiments comply with the current laws of Germany and Poland.

Received: 21 March 2014; accepted: 09 September 2014; published online: 08 October 2014.

Citation: Budahn H, Barański R, Grzebelus D, Kiełkowska A, Straka P, Metge K, Linke $B$ and Nothnagel $T$ (2014) Mapping genes governing flower architecture and pollen development in a double mutant population of carrot. Front. Plant Sci. 5:504. doi: $10.3389 / \mathrm{fpls} .2014 .00504$

This article was submitted to Plant Genetics and Genomics, a section of the journal Frontiers in Plant Science.

Copyright (C) 2014 Budahn, Barański, Grzebelus, Kiełkowska, Straka, Metge, Linke and Nothnagel. This is an open-access article distributed under the terms of the Creative Commons Attribution License (CC BY). The use, distribution or reproduction in other forums is permitted, provided the original author(s) or licensor are credited and that the original publication in this journal is cited, in accordance with accepted academic practice. No use, distribution or reproduction is permitted which does not comply with these terms. 